\title{
Acute transverse myelitis after SARS-CoV-2 infection: a rare complicated case of rapid onset paraplegia
}

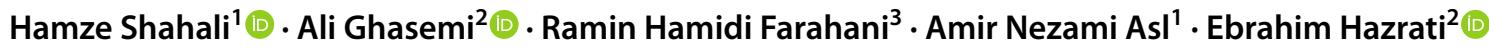

Received: 6 November 2020 / Revised: 21 January 2021 / Accepted: 1 February 2021 / Published online: 1 March 2021

(c) Journal of NeuroVirology, Inc. 2021

\begin{abstract}
A 63-year-old Caucasian male, known case of controlled type 2 diabetes, chronic renal failure, and ischemic heart disease, was presented with weakness and loss of movement in lower limbs, an absent sensation from the chest below, constipation, and urinary retention. About 4 days before these symptoms, he experienced a flu-like syndrome. Suspicious for COVID-19, his nasopharyngeal specimen's reverse transcription-polymerase chain reaction (RT-PCR) resulted positive. Chest X-ray and HRCT demonstrated severe pulmonary involvement. Immediately, he was admitted to the emergency ward, and the treatment was started according to the national COVID-19 treatment protocol. Subsequently, diagnostic measures were taken to investigate the patient's non-heterogeneous peripheral (spinal) neuromuscular manifestations. Brain CT scan and MRI were normal, but spinal MRI with gadolinium contrast showed extensive increased T2 signal involving central gray matter and dorsal columns, extended from C7 to T12 with linear enhancement in the sagittal plane, posteriorly within the mid and lower thoracic cord. The CSF specimen demonstrated pleocytosis, positive RT-PCR for SARS-CoV-2, and elevated IgG index. Clinical presentation, MRI, CSF, and laboratory findings prioritized the acute transverse myelitis (ATM) as a probable complication of COVID-19 infection over other differential diagnoses. Intravenous methylprednisolone and, subsequently, IV human immunoglobulin were added to the treatment regimen. In the end, the complete resolution of dysesthesia, urinary retention, and constipation were achieved. After continuous and extended respiratory and motor rehabilitation programs, he was discharged asymptomatic.
\end{abstract}

Keywords SARS-CoV-2 $\cdot$ Acute transverse myelitis · COVID-19

Ebrahim Hazrati

dr.hazrati.e@gmail.com

Hamze Shahali

hamze.shahali@ajaums.ac.ir

Ali Ghasemi

1ali1ghasemi0@gmail.com

Ramin Hamidi Farahani

Rgsramin@yahoo.com

Amir Nezami Asl

Amir.nezamiasl@gmail.com

1 Aerospace and Sub-Aquatic Medical Faculty, Aja University of Medical Sciences, Tehran, Iran

2 Dept of Anesthesiology and Intensive Care, Medical Faculty, Aja University of Medical Sciences, Tehran, Iran

3 Dept of Infectious and Tropical Diseases, Medical Faculty, Aja University of Medical Sciences, Tehran, Iran

\section{Introduction}

SARS-CoV-2 infection (COVID-19) has become a pandemic, and currently, there are no definite treatment options. This infection mostly affects the respiratory system, but extra respiratory multi-systemic involvement has also been reported (Casadevall and Pirofski 2020; Wang et al. 2020; Farahani et al. 2020). Neurological manifestations are rare but reported during the acute phase and the treatment period (Ashrafi et al. 2020 April). In particular, SARS$\mathrm{CoV}-2$ is a neurotrophic and neuro-invasive virus, and experimental animal studies have reported the association of acute flaccid paralysis (AFP) and demyelination with this infection (Brison et al. 2011). However, SARS-CoV-2 infection has not been reported as a cause of AFP until now (Dominguez et al. 2009). Nonetheless, few studies have reported post-infectious acute myelitis as a possible COVID19 complication (Zhao et al. 2020; Baghbanian and Namazi 
2020). Here, we report a case of early-onset ATM following SARS-CoV-2 infection.

\section{Case report}

A 63-year-old Caucasian man, with no history of trauma, experienced a sudden loss of control over both lower limbs, absent sensation from the chest below, constipation, and urinary retention, after the onset of a flu-like syndrome. The patient stated that he had fever, fatigue, sore throat, and runny nose, but no shortness of breath, about 4 days before his neurological complications. He was a known case of controlled type 2 diabetes, chronic renal failure, and ischemic heart disease. On arrival, he had $38.6{ }^{\circ} \mathrm{C}$ oral temperature, a blood pressure of $155 / 95 \mathrm{mmHg}, 98$ heartbeats per minute, a respiratory rate of 21 breaths per minute, and $91 \%$ saturation in pulse oximetry on room air. No prominent abnormal finding in cranial nerves or neck rigidity was detected. Although normal muscle bulk was found in all four extremities, both lower limbs were hypotonic. Besides, while muscle forces were 5/5 in upper limbs, they were graded as $1 / 5$ in both lower limbs. All modalities of sensation were diminished below the $\mathrm{T} 8$ level. The perianal sensation was absent; however, deep anal pressure awareness and bulbocavernosus reflex were present. Distal tendon reflexes were bilaterally absent in lower limbs but normal in upper limbs. Besides, superficial abdominal reflexes were present in upper quadrants and absent in lower quadrants. Plantar reflexes were bilaterally mute, and cerebellar signs were absent. Also, bilateral pathological signs were negative.

Regarding the COVID-19 outbreak, RT-PCR was done on a swab test of nasopharyngeal mucosa and reported positive. Subsequently, chest X-ray and HRCT revealed severe bilateral pulmonary involvement (Fig. 1).

According to the then national COVID-19 treatment protocol, hydroxychloroquine (400 $\mathrm{mg}$ PO BID on the 1st day and then $200 \mathrm{mg}$ BID for 10 days), azithromycin (500 mg PO daily for 5 days), and ritonavir (PO daily for 10 days) were administered. Furthermore, neurological manifestations were investigated.
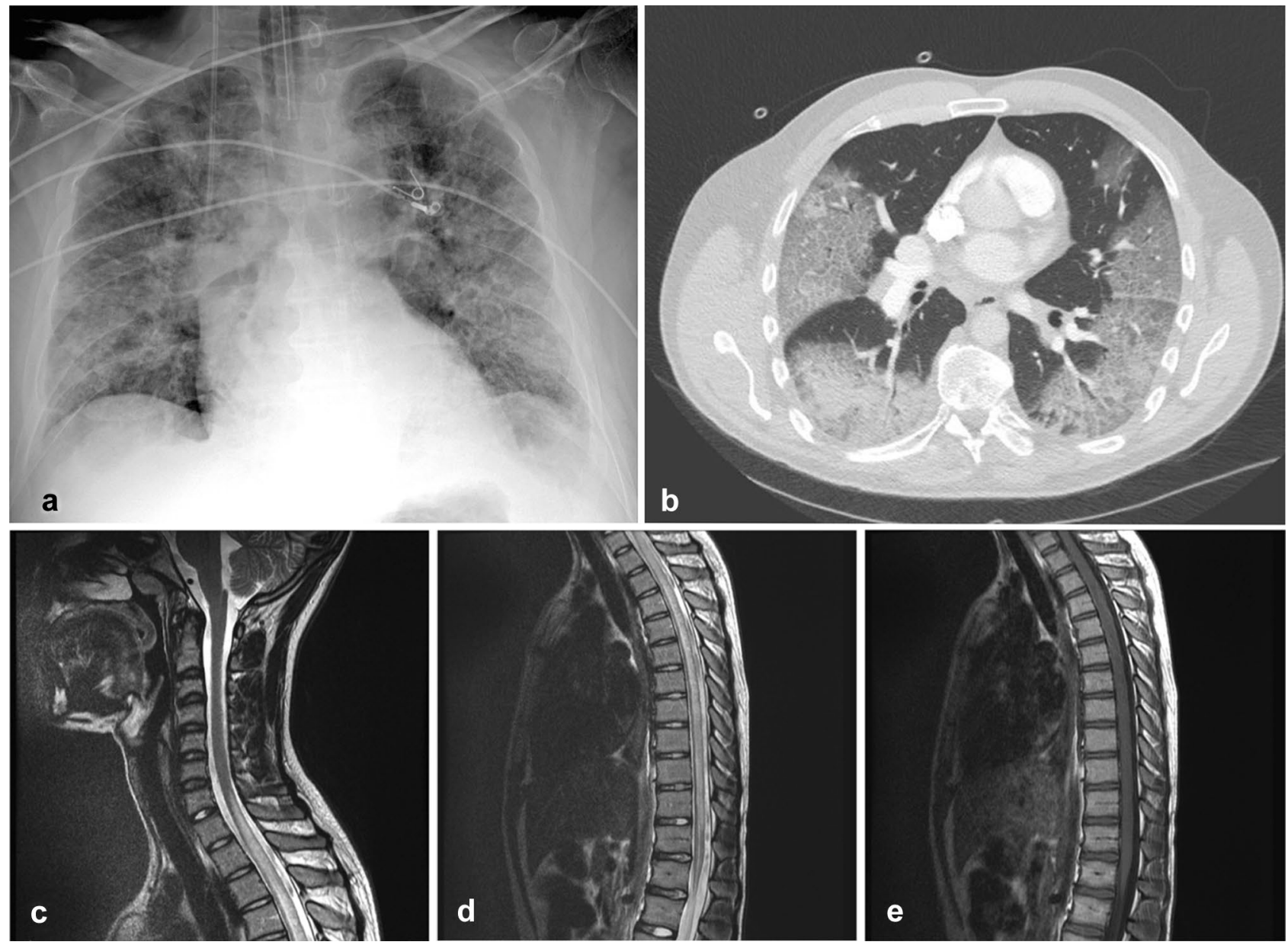

Fig. 1 a Posteroanterior chest X-ray; $\mathbf{b}$ a slice of chest HRCT scan; $\mathbf{c}-\mathbf{e}$ spinal MRI with gadolinium contrast agent, $\mathbf{c}, \mathbf{d}$ sagittal T2 views, $\mathbf{e}$ sagittal $\mathrm{T} 1$ view 
Brain CT scan, MRI, and contrast-enhanced MRI were reported as normal; thus, a lumbar puncture was done. Significant CSF findings and main laboratory results are summarized in Table 1. Besides, spinal contrast-enhanced MRI showed an extensive increased $\mathrm{T} 2$ signal that involved central gray matter and dorsal columns. The cord was expanded between C7 and T12. Also, a linear enhancement in the sagittal plane was seen posteriorly within the mid and lower thoracic cord (Fig. 1).
Table 1 Significant laboratory findings

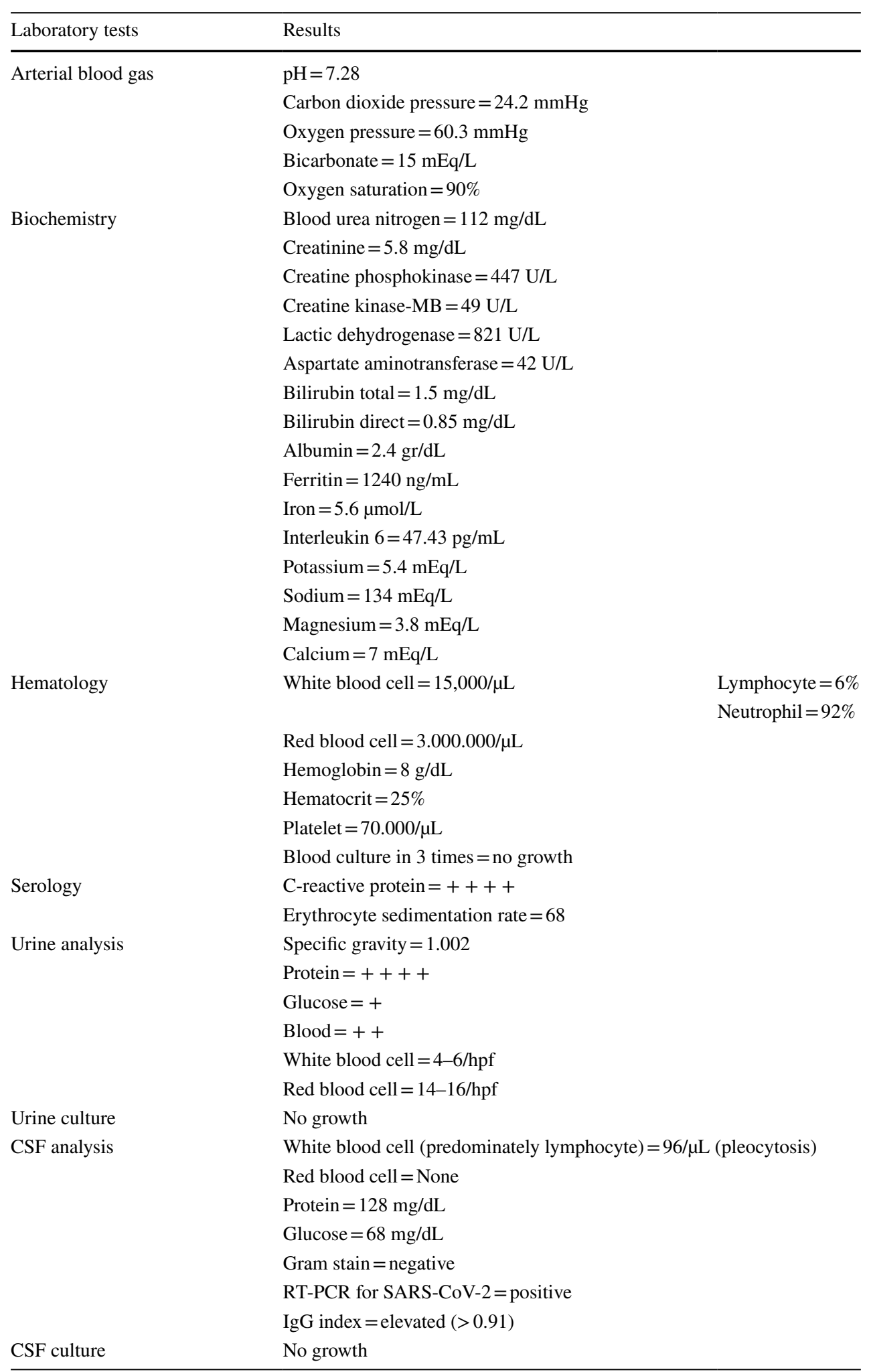


Table 2 Differential diagnoses and the tests used for ruling them out

\begin{tabular}{|c|c|c|c|}
\hline Categories & Causes & & Ruled Out Methods \\
\hline \multirow[t]{4}{*}{ Para-infectious } & \multirow[t]{3}{*}{ Bacterial } & $\begin{array}{l}\text { Mycoplasma pneumoniae, chla- } \\
\text { mydia pneumonia }\end{array}$ & Negative serum IgM \\
\hline & & Mycobacterium tuberculosis & $\begin{array}{l}\text { Negative tuberculin skin test } \\
\text { (Mantoux method) and T cells of } \\
\text { tuberculosis }\end{array}$ \\
\hline & & Syphilis & Negative VDRL and RPR test \\
\hline & Viral & $\begin{array}{l}\text { Varicella-Zoster (VZV), human } \\
\text { immunodeficiency viruses (HIV), } \\
\text { Epstein-Barr (EBV), influenza B } \\
\text { virus, adenovirus, coxsackievirus, } \\
\text { influenza A virus, parainfluenza } \\
\text { virus, cytomegalovirus (CMV), } \\
\text { respiratory syncytial virus }\end{array}$ & Negative serum IgM \\
\hline \multirow[t]{5}{*}{$\begin{array}{l}\text { Systemic inflammatory or } \\
\text { autoimmune diseases }\end{array}$} & \multicolumn{2}{|l|}{ Systemic lupus erythematosus (SLE) } & $\begin{array}{l}\text { Negative serum anti-ds-DNA, anti- } \\
\text { Sm antibodies, and anti-nucleo- } \\
\text { some antibodies }\end{array}$ \\
\hline & \multicolumn{2}{|l|}{ Sjogren's syndrome } & $\begin{array}{l}\text { Negative serum anti-SS-A/RO, Anti- } \\
\text { SS-B/LA }\end{array}$ \\
\hline & \multicolumn{2}{|l|}{ Antiphospholipid syndrome } & $\begin{array}{l}\text { Negative serum antiphospholipid } \\
\text { antibody and anti-cardiolipin } \\
\text { antibody }\end{array}$ \\
\hline & \multicolumn{2}{|l|}{ Neuro-sarcoidosis } & $\begin{array}{l}\text { Normal serum CEA, ACE, and } \\
\text { calcium }\end{array}$ \\
\hline & \multicolumn{2}{|l|}{ Systemic sclerosis } & $\begin{array}{l}\text { Negative serum anti-centromere } \\
\text { antibody and anti-scl70 }\end{array}$ \\
\hline \multirow[t]{3}{*}{ CNS autoimmune disorders } & \multicolumn{2}{|l|}{ Multiple sclerosis (MS) } & $\begin{array}{l}\text { Normal CSF oligoclonal bands and } \\
\text { serum anti-MOG antibodies }\end{array}$ \\
\hline & \multicolumn{2}{|l|}{ Neuromyelitis optica (NMO) } & Normal serum NMO-IgG (AQP4) \\
\hline & \multicolumn{2}{|c|}{ Acute disseminated encephalomyelitis (ADEM) and cortical encephalitis } & $\begin{array}{l}\text { Normal serum anti-MOG antibodies } \\
\text { and brain MRI }\end{array}$ \\
\hline Trauma & \multicolumn{2}{|c|}{ Spinal cord compression (due to epidural abscess, tumor, or hematomas) } & $\begin{array}{l}\text { No evidence of any space-occupying } \\
\text { or compressive condition in spinal } \\
\text { cord MRI }\end{array}$ \\
\hline
\end{tabular}

Subsequently, comprehensive laboratory tests were done to rule out the differential diagnoses (Table 2). Regarding the clinical presentation and paraclinical findings, acute transverse myelitis (ATM) as a probable complication of COVID-19 was considered the most plausible diagnosis.

After establishing the diagnosis, IV methylprednisolone ( $1 \mathrm{~g} /$ day for 3 days and then tapered to $1 \mathrm{mg} / \mathrm{kg} /$ day) was added to the treatment regimen. Over the next 3 days, his clinical condition deteriorated. He experienced intensifying lower thoracic pain, progressive hypoesthesia, and gradual debilitating dysesthesia characterized by numbness and ice-cold sensation. Subsequently, methylprednisolone was replaced by IV human immunoglobulin (25 $\mathrm{g}$ daily for 3 days), resulting in drastic clinical improvement within the next days. One week later, the patient was able to walk unassisted, with complete resolution of neurologic manifestations. Five weeks after admission, with regular and thorough rehabilitation sessions, he was discharged home asymptomatic.

\section{Discussion}

Acute transverse myelitis is characterized by an acute inflammatory process of the spinal cord that can be classified into various etiologically distinct groups. Myelitis with a suspected autoimmune basis is the most common form of ATM that usually occurs as a post- or para-infectious condition, while viral infections are responsible for approximately $25-40 \%$ of these cases. Respiratory and intestinal infections are notable potential triggers of ATM, but some post-vaccinal cases have also been reported (Zhu et al. 2020; Guan et al. 2019; Lu et al. 2020).

The clinical picture of ATM includes acute partial or complete motor, sensory, and autonomic spinal cord 
dysfunction. In a few patients, however, the disease has an ascending course with the risk of asphyxia when upper cervical segments (C3-C5) are involved.

A plausible explanation for the post- or para-infectious or post-vaccinal ATM is that the immunologic process that targets the infectious organism also attacks the central and peripheral nervous systems. A subsequent viral inflammatory process could result in neuronal death or spinal tract lesions. Moreover, a recent study showed that SARS-CoV-2 could enter human cells through ACE2 receptors. Intriguingly, ACE2 receptors are also expressed on the membrane of spinal cord neurons, suggesting that SARS-CoV-2 might be implicated in acute myelitis by the ACE2 receptors (Zhao et al. 2020).

Differential diagnoses of evolving myelopathy are various (Table 2), and viral myelitis can be a challenging diagnosis or, in some cases, the diagnosis of exclusion. Initially, compressive etiologies should be excluded. Also, clinical features, laboratory studies (especially CSF), and imaging findings provide useful information for neurological conditions (Kaplin et al. 2005).

Treatment of ATM is still controversial and should be tailored to the individual patient. The efficacy of antivirals, high doses of IV methylprednisolone, and IVIg in viral immune-mediated neurological disorders, namely ATM, have been reported in the literature (Kaplin et al. 2005).

In this paper, we reported a complicated case of earlyonset ATM following a SARS-CoV-2 respiratory infection associated with several diagnostic, therapeutic, and rehabilitative challenges. We only found one study reporting post-infectious acute myelitis as a possible COVID-19 complication (Zhao et al. 2020). Because of the potentially grave and poor neurologic outcomes, sharing the experiences of these patients is vital. We suggest that SARS-CoV-2 can produce different multisystemic involvements via immune-mediated processes that might be the culprit when a patient presents with acute onset of neurological manifestations, especially after microbial infections or vaccinations (Zhao et al. 2020; Karakonstantis et al. 2017).

\section{References}

Ashrafi MR, Azizimalamiri R, Shervin Badv R, Tavasoli AR, Nikkhah A, Montazerlotfelahi $\mathrm{H}$ et al (2020) Coronavirus, its neurologic manifestations, and complications. Iran J Pediatr 30(2):e102569. https://doi.org/10.5812/ijp.102569
Baghbanian SM, Namazi F (2020) Post COVID-19 longitudinally extensive transverse myelitis (LETM)-a case report. Acta Neurol Belg 1-2

Brison E, Jacomy H, Desforges M, Talbot PJ (2011) Glutamate excitotoxicity is involved in the induction of paralysis in mice after infection by a human coronavirus with a single point mutation in its spike protein. J Virol 85(23):12464-12473. https://doi.org/10.1128/JVI.05576-11.[PubMed:21957311]. [PubMedCentral:PMC3209392]

Casadevall A, Pirofski LA (2020) The convalescent sera option for containing COVID-19. J Clin Invest 130:1545-1548

Dominguez SR, Robinson CC, Holmes KV (2009) Detection of four human coronaviruses in respiratory infections in children: a one-year study in Colorado. J Med Virol 81(9):1597-1604. https://doi.org/10.1002/jmv.21541.[PubMed:19626607]. [PubMedCentral:PMC2879166]

Farahani RH, Gholami M, Hazrati E, Hosseini Rouzbahani N, Hejripour Z, Soleiman-Meigooni S et al (2020) Clinical features of ICU admitted and intubated novel corona virus-infected patients in Iran. Arch Clin Infect Dis 15(2):e103295

Guan WJ, Ni ZY, Hu Y et al (2020) Clinical characteristics of coronavirus disease 2019 in China. N Engl J Med 382(18):1708-1720

Kaplin AI, Krishnan C, Deshpande DM, Pardo CA, Kerr DA (2005) Diagnosis and management of acute myelopathies. Neurologist 11(1):2-18. https://doi.org/10.1097/01.nrl.0000149975.39201.0b.)

Karakonstantis S, Galani D, Maragou S, Koulouridi A, Kalemaki D, Lydakis C (2017) A rare case of acute transverse myelitis associated with Staphylococcus aureus bacteremia and osteomyelitis. International Spinal Cord Society. 3:17029. https://doi.org/10.1038/scsandc.2017.29

$\mathrm{Lu} \mathrm{R}$, Zhao X, Li J et al (2020) Genomic characterisation and epidemiology of 2019 novel coronavirus: implications for virus origins and receptor binding. Lancet 395:565-574

Wang D, Hu B, Hu C et al (2020) Clinical characteristics of 138 hospitalized patients with 2019 novel coronavirus-infected pneumonia in Wuhan, China. JAMA 323:1061-1069

Zhao K, Huang J, Dai D, Feng Y, Liu L, Nie S (2020) Acute myelitis after SARS-CoV-2 infection :a case report. medRxiv preprint. Mar 2020. https://doi.org/10.1101/2020.03.16.20035105

Zhu N, Zhang D, Wang W et al (2020) A novel coronavirus from patients with pneumonia in China, 2019. N Engl J Med 382:727-733

Publisher's Note Springer Nature remains neutral with regard to jurisdictional claims in published maps and institutional affiliations. 